\title{
Expression profile of Galp, alarin and their receptors in rat adrenal gland
}

\author{
Marianna Tyczewska ${ }^{1, A-F}$, Paulina Milecka 2,B,C,F, Marta Szyszka ${ }^{1, B, C, F}$, Piotr Celichowski ${ }^{1, B, C, F}$, \\ Karol Jopek1,B,C,F, Hanna Komarowska ${ }^{3, B, C, F}$, Ludwik Kazimierz Malendowicz ${ }^{1, E, F}$, Marcin Ruciński ${ }^{1, A, F}$ \\ ${ }^{1}$ Department of Histology and Embryology, Poznan University of Medical Sciences, Poland \\ ${ }^{2}$ Central Laboratory of Microbiology, H. Swiecicki Clinical Hospital at the Poznan University of Medical Sciences, Poland \\ ${ }^{3}$ Department of Endocrinology, Metabolism and Internal Medicine, Poznan University of Medical Sciences, Poland \\ A - research concept and design; $\mathrm{B}$ - collection and/or assembly of data; $\mathrm{C}$ - data analysis and interpretation; \\ $D$ - writing the article; $E$ - critical revision of the article; $F$ - final approval of the article
}

\section{Address for correspondence}

Marianna Tyczewska

E-mail: maritycz@ump.edu.pl

\section{Funding sources}

Grant No. 2015/17/D/NZ4/02294, National Science

Centre, Poland.

\section{Conflict of interest}

None declared

Received on June 26, 2018

Reviewed on July 9, 2018

Accepted on September 10, 2018

Published online on March 6, 2019

Cite as

Tyczewska M, Milecka P, Szyszka M, et al. Expression profile of Galp, alarin and their receptors in rat adrenal gland. Adv Clin Exp Med. 2019;28(6):737-746.

doi:10.17219/acem/95039

DOI

10.17219/acem/95039

\section{Copyright}

Copyright by Author(s)

This is an article distributed under the terms of the

Creative Commons Attribution Non-Commercial License

(http://creativecommons.org/licenses/by-nc-nd/4.0/)

\begin{abstract}
Background. Galanin-like peptide (Galp) and alarin (Ala) are 2 new members of the galanin peptide family. Galanin (Gal), the "parental" peptide of the entire family, is known to regulate numerous physiological processes, including energy and osmotic homeostasis, reproduction, food intake, and secretion of adrenocortical hormones. Galp and Ala are known to regulate food intake. In the rat, Galp mRNA has been found in the brain, exclusively in the hypothalamic arcuate nucleus (ARC) and median eminence, which are involved in the regulation of energy homeostasis. Alarin-like immunoreactivity is present in the locus coeruleus (LC) and the ARC of rats and mice.
\end{abstract}

Objectives. The aim of the study was to investigate the expression of Ala, Galp and their receptors in the organs of the hypothalamo-pituitary-adrenal (HPA) axis of the rat.

Material and methods. The expression of the examined genes was measured in different models of adrenal growth of the rat in vivo (postnatal ontogenesis, compensatory adrenal growth, adrenocortical regeneration, adrenocorticotropic hormone (ACTH) administration). The expression was evaluated using the Affymetrix ${ }^{\circledR}$ microarray system or quantitative polymerase chain reaction (qPCR).

Results. The expression of Ala gene was observed in each organ of the HPA axis (the hypothalamus, hypophysis and adrenal gland). The elevated level of expression of this gene was observed in the pituitary of 2-day rats, while very low levels of Ala mRNA were observed in the adrenals. Galp mRNA expression was observed only in the hypothalamus and the hypophysis during postnatal ontogenesis. The expression of Gal receptors was demonstrated in the hypothalamus, the hypophysis and the adrenal gland. In different compartments of the adrenal glands of adult, intact male and female rats, the expression of Ala, Galp and galanin receptor 1 (Galr7) genes was negligible, but the expression of galanin receptor 2 (Galr2), galanin receptor 3 (Galr3) and neurotrophic receptor tyrosine kinase 2 (Ntrk2) genes was noticeable.

Conclusions. The examined genes showed different expression levels within the studied HPA axis; some of them were neither expressed in the hypothalamus or the pituitary gland, nor in the adrenal gland.

Key words: galanin-like peptide, alarin, adrenal gland 


\section{Introduction}

Galanin (Gal), a biologically active peptide composed of 29 amino acid residues, was discovered in $1983 .{ }^{1}$ This peptide is widely distributed in the nervous system and gut, and acts through 3 subtypes of $G$ protein-coupled receptors, named galanin receptor 1 (Galr1), galanin receptor 2 (Galr2) and galanin receptor 3 (Galr3). ${ }^{2}$

Further research allowed the identification of other proteins that make up the common 'galanin peptide family'. In 1999, Ohtaki et al. identified a new peptide - galaninlike peptide (Galp). ${ }^{3}$ A few years later, a splice variant of Galp gene was isolated and named alarin (Ala). Galaninlike peptide, a 60-amino acid-long peptide, was first isolated and cloned from porcine hypothalamus as an endogenous ligand of the galanin type 2 receptor (Galr2). ${ }^{3,4}$ Alarin is a 25-amino acid peptide, formed in the process of modification of GALP mRNA as a result of exclusion of exon 3, was first identified in the gangliocytes of human neuroblastic tumors. ${ }^{5}$ Over the last 20 years, the expression of Galp and Ala mRNAs and their function have been analyzed. Both peptides are known to regulate food intake, for example centrally administered Galp inhibited feeding in mice, while intraparaventricular (ipv.) Galp injection stimulated food intake in rats. ${ }^{6,7}$ A high expression of Galp was observed in porcine gastrointestinal tract. In rat brain, Galp mRNA has been found in cell bodies residing exclusively in the hypothalamic arcuate nucleus (ARC) and median eminence. ${ }^{8-10}$ In this context, it should be noted that both Gal and Galp regulate a number of physiological processes, including arousal/sleep regulation, energy and osmotic homeostasis, reproduction, and food intake. ${ }^{11-13}$

Taking into account the role of Gal and Galp in the regulation of energy homeostasis, it should be stressed that some experimental data indicates a correlation between such peptides and the adrenal cortex function. It is known that numerous neuropeptides affect, directly or indirectly, the secretion of corticosteroids. On the other hand, steroid hormones of the adrenal gland regulate the synthesis and secretion of various orexigenic and anorexigenic peptides. For example, both corticosteroid and dexamethasone increase the expression in the hypothalamus and the secretion of orexigenic neuropeptide Y (NPY). ${ }^{14}$ Furthermore, orexins exert a potent stimulating effect on corticosteroid secretion..$^{15}$

Numerous studies indicate that peptides involved in the regulation of energy homeostasis also regulate the growth, differentiation and secretory function of the adrenal cortex. Regarding this, the role of Gal in the regulation of the hypothalamo-pituitary-adrenal (HPA) axis is relatively well known. ${ }^{16} \mathrm{Gal}$ and its receptors are expressed in the hypothalamus, the anterior pituitary and the adrenal medulla. Experimental data indicates that Gal stimulates the HPA axis acting on the secretion of corticotropin-releasing hormone $(\mathrm{CRH})$ and adrenocorticotropic hormone $(\mathrm{ACTH})$, and exerts a direct stimulating effect on the secretion of corticosterone by isolated adrenocortical cells. Unlike Gal, the expression of genes of other galanin peptide family members within the HPA axis and the role of the proteins encoded by them in the regulation of the secretory function of the HPA axis are not known well.

\section{Objectives}

The aim of the study was to investigate the expression of Ala, Galp and their receptors Galr1, Galr2, Galr3, and neurotrophic receptor tyrosine kinase 2 (Ntrk) in the organs of the HPA axis. The studies were performed on intact rats of both sexes, during ontogenesis and in altered adrenal cortex function caused by ACTH administration, unilateral adrenalectomy and enucleation of the gland.

\section{Material and methods}

\section{Animals and reagents}

Male and female Wistar rats from the Laboratory Animal Breeding Center, Department of Toxicology, Poznan University of Medical Sciences, Poland, were used. The number of rats, their sex, age and body mass are given in the descriptions of the individual experiments or the descriptions of relevant figures. The study protocol was approved by the Local Ethics Committee for Animal Studies (No. LKE-11/2015 and LKE-24/2015). Animals were maintained under standardized conditions of light (12:12 h light-dark cycle, illumination onset at 6.00 a.m.), with the airflow exchange $8-10$ times/h, at $55-60 \%$ air humidity and the temperature of $22 \pm 1^{\circ} \mathrm{C}$, with free access to standard pellets and tap water. ${ }^{17}$ Unless otherwise stated, all reagents were obtained from Sigma-Aldrich (St. Louis, USA) or from Avantor Performance Materials Poland S.A. (Gliwice, Poland). Animals were decapitated between 9.00 a.m. and 10.00 a.m.

\section{Experiments}

Expression analysis of Ala, Galp and their receptors in the hypothalamo-pituitary-adrenal axis during postnatal ontogenesis

Organs were harvested from intact male rats 2, 21, 60, 120 , and 360 days after birth (postnatal ontogenesis). The animals were decapitated and the tissues quickly removed. Fragments of the hypothalamus were collected as described by Rucinski et al. ${ }^{18}$ The neural lobe was removed from the pituitary gland using a stereoscopic microscope (ZEISS, Oberkochen, Germany), while the adrenals were cleaned of adherent fat and samples were taken from the entire gland. All samples were immersed in RNAl$\operatorname{ater}^{\circledR}$ (Thermo Fisher Scientific, Inc., Waltham, USA) and 
frozen at $-80^{\circ} \mathrm{C}$ for quantitative polymerase chain reaction (qPCR) analysis. Each age group consisted of 5 animals.

Expression analysis of Ala, Galp and their receptors in different compartments of the adrenal glands of adult, intact male and female rats

The study was performed on tissues used in previous research. ${ }^{19}$ Intact adult female and male Wistar rats (12 weeks old; body weight: $120-150 \mathrm{~g}$ ) were used. The females were used in the estrus cycle phase, which was determined on the basis of the cell types observed in the vaginal smear. The animals (females: $n=6$, males: $n=6$ ) were decapitated, and the adrenals were removed, freed of adherent fat and divided into 3 zones: zona glomerulosa (ZG), zona fasciculata/reticularis (ZF/R) and medulla (M). After that, the samples were sunk in RNAlater and frozen at $-80^{\circ} \mathrm{C}$ for microarray and qPCR analysis. Identification of adrenal compartments was anatomy-based and conducted under a stereomicroscope.

Expression analysis of Ala, Galp and their receptors in the hypothalamo-pituitary-adrenal axis of rats administered adrenocorticotropic hormone

The experiment was performed on 10 adult (3-4 months old; body weight: 250-300 g) male rats. Adrenocorticotropic hormone (Cortrosyn ${ }^{\circledR}$; Organon Pharmaceuticals, West Orange, USA) was administered by intraperitoneal (ip.) injection at a dose of $2.5 \mu \mathrm{g} / 100 \mathrm{~g}$. Control rats were administered $0.2 \mathrm{~mL}$ of physiological saline $(0.9 \% \mathrm{NaCl})$. Each group consisted of 5 animals. The rats were decapitated $1 \mathrm{~h}$ after injection. The hypothalami, as well as the pituitary and adrenal glands were collected as described above, preserved in RNAlater and stored at $-80^{\circ} \mathrm{C}$ for qPCR analysis. The dose of ACTH was selected according to previous studies. ${ }^{20}$

\section{Enucleation-induced adrenocortical regeneration}

Female Wistar rats (18 animals; final body weight: 100$150 \mathrm{~g})$ were used. ${ }^{21}$ In the rats, under standard ketamine (100 mg/kg, ip.) and xylazine $(10 \mathrm{mg} / \mathrm{kg}$, ip.) anesthesia, via the dorsal approach, both adrenal glands were enucleated according to the classic method. ${ }^{21}$ The operated rats were given $0.9 \% \mathrm{NaCl}$ to drink for 3 days. One, 2, 3, 5 , 8 , or 15 days after the surgery, the rats were sacrificed (3 per group), and their regenerating adrenals were immediately removed, freed of adherent fat, sunk in RNAlater, and stored at $-80^{\circ} \mathrm{C}$ for microarray and qPCR analysis. The adrenals from sham-operated rats (removed on day 1 after the surgery) were used as control glands. ${ }^{21}$

\section{Compensatory adrenal growth}

The experiment was described earlier. ${ }^{17}$ In brief, under standard ketamine (100 mg/kg, ip.) and xylazine $(10 \mathrm{mg} / \mathrm{kg}$, ip.) anesthesia, left adrenal glands were removed from the dorsal incision at the last rib height of the rat (left hemiadrenalectomy). The decapitation of the animals was performed 24 and $72 \mathrm{~h}$ after the procedure (experimental group). The animals from the sham-operated group were decapitated $24 \mathrm{~h}$ after the sham surgery. The adrenals were removed, the samples were sunk in RNAlater and frozen at $-80^{\circ} \mathrm{C}$ for microarray and $\mathrm{qPCR}$ analysis. In each group there were 10 rats. The surgical procedures as well as the completion of the experiment were carried out between 10 a.m. and 11 a.m.

\section{Microarray analysis}

The entire analysis procedure was described in previous publications. ${ }^{19,21}$ Microarray analysis was used in the experiments regarding the compartments of the adrenal glands of adult, intact male and female rats, the enucleation-induced adrenocortical regeneration and the compensatory growth of the adrenal gland. From the adrenal glands, total RNA was isolated using the Tri-Reagent method and purified on columns (RNeasy ${ }^{\circledR}$ Mini Kit; Qiagen, Hilden, Germany). The RNA quantity and quality were analyzed with gel electrophoresis and spectrophotometry (NanoDrop ${ }^{\circledR}$ ND-1000; Thermo Fisher Scientific, Inc.). Microarray analyses were performed using Affymetrix ${ }^{\circledR}$ Rat Gene 1.1 ST Array Strip (Thermo Fisher Scientific, Inc.). ${ }^{21}$ The obtained CEL files were imported into downstream data analysis software (Bioconductor package of R language (https://www.bioconductor.org/). Every CEL file was merged with a description file. To correct for background, to normalize and summarize the results, the authors used the Robust Multi-array Averaging (RMA) method. Statistical significance of the expression levels of the analyzed genes was examined using moderated t-statistics from the empirical Bayes method. The obtained p-values were corrected for multiple comparisons using the Benjamini and Hochberg's false discovery rate (FDR) (a statistical method incorporated into Bioconductor calculations). ${ }^{22}$

\section{Ribonucleic acid isolation}

From the obtained tissues (hypothalami, pituitary glands, adrenals) total RNA was extracted using NucleoSpin ${ }^{\circledR}$ RNA mini spin columns (MACHEREY-NAGEL GmbH \& Co. KG, Düren, Germany). The RNA isolation procedure was performed as previously described. ${ }^{19}$ To each sample $150 \mu \mathrm{L}$ of chloroform was added and the samples were centrifuged for $10 \mathrm{~min}$ at $12,000 \times \mathrm{g}$ at $4^{\circ} \mathrm{C}$. The supernatant was collected and $350 \mu \mathrm{L}$ of $70 \%$ ethanol was added to each sample. The mixture was transferred to pure mini-columns and centrifuged for $1 \mathrm{~min}$ at 11,000 $\times \mathrm{g}$. The next 3 steps included the addition of a rinsing buffer at appropriate concentrations. After each addition, the samples were centrifuged again under the abovementioned conditions ( $30 \mathrm{~s}$ - the first 2 steps or $2 \mathrm{~min}-$ the $3^{\text {rd }}$ step). At the final stage of the procedure, the mini-columns 
were placed in clean tubes and to each tube $30 \mu \mathrm{L}$ of water was added. The amount of total RNA was determined by optical density at $260 \mathrm{~nm}$ and its purity was estimated by $260 / 280 \mathrm{~nm}$ absorption ratio (>1.8) (NanoDrop spectrophotometer). The samples were stored at $-80^{\circ} \mathrm{C}$ for further qPCR analysis.

\section{Reverse transcription polymerase chain reaction}

Reverse transcription was performed using Transcriptor High Fidelity cDNA Synthesis Kit (Roche, Basel, Switzerland) at the temperature of $42^{\circ} \mathrm{C}$ for $60 \mathrm{~min}$ (Thermocycler UNO II; Biometra (Göttingen, Germany). The primers were designed by Primer 3 software (Whitehead Institute for Biomedical Research, Cambridge, USA) and purchased from the Laboratory of DNA Sequencing and Oligonucleotide Synthesis, Institute of Biochemistry and Biophysics, Polish Academy of Sciences, Warszawa, Poland (Table 1). Only Ala primer sequences were taken from the publication of Santic et al. ${ }^{23}$

\section{Quantitative polymerase chain reaction}

The expression levels of the studied genes (Table 1) were measured by means of real-time qPCR using the LightCycler $^{\circledR} 2.0$ instrument with 4.05 software version (Roche). Using the primers presented in Table 1, the SYBR ${ }^{\circledR}$ Green detection system was applied according to the specific protocol, except for Ala. Each $20 \mu \mathrm{L}$ of the reaction mixture contained $4 \mu \mathrm{L}$ template cDNA (standard or control), $0.5 \mu \mathrm{M}$ of each gene-specific primer and a previously determined optimum $\mathrm{MgCl}_{2}$ concentration (3.5 $\mu \mathrm{M}$ for 1 reaction). The LightCycler ${ }^{\circledR}$ FastStart DNA Master SYBR Green I mix (Roche) was used. The real-time qPCR program included a 10-minute initial denaturation step to activate Taq DNA Polymerase $\left(95^{\circ} \mathrm{C}\right)$, followed by a 3-step amplification program - denaturation at $95^{\circ} \mathrm{C}$ for $10 \mathrm{~s}$, annealing at $58^{\circ} \mathrm{C}$ or $60^{\circ} \mathrm{C}$ for $5 \mathrm{~s}$, and extension at $72^{\circ} \mathrm{C}$ for $10 \mathrm{~s}$. Only the qPCR analyses to detect Ala mRNA expression levels were performed using the data from Santic et al. ${ }^{23}$ The alarin real-time qPCR program was as follows: A 10-minute initial denaturation step to activate Taq DNA Polymerase $\left(95^{\circ} \mathrm{C}\right)$, followed by a 2 -step amplification program - denaturation at $95^{\circ} \mathrm{C}$ for $5 \mathrm{~s}$ and annealing at $60^{\circ} \mathrm{C}$ for $20 \mathrm{~s}$. The specificity of the reaction products was checked by the determination of melting points (transition rate: $0.1^{\circ} \mathrm{C} / \mathrm{s}$ ).

\section{Statistics}

Microarray data was statistically evaluated with a moderated t-statistics test with Benjamini and Hochberg's FDR correction. ${ }^{24}$ The qPCR results were presented as means \pm standard error of the mean (SEM). For multiple comparisons, statistical analysis of the data was performed using one-way analysis of variance (ANOVA) followed by Tukey's post-hoc test. The calculations were performed using $\mathrm{R} \times 64$ software $\mathrm{v}$. 3.4.1 with the multicomp library. Following one-way ANOVA, if $\mathrm{p}<0.05$ was obtained, Tukey's post-hoc test was performed and differences were considered to be statistically significant at $\mathrm{p}<0.05$. The results of Tukey's post-hoc test are marked by letters $(\mathrm{a}, \mathrm{b}, \mathrm{c})$. Groups sharing the same letter are not significantly different from each other according to Tukey's post-hoc test.

Table 1. Conventional reverse transcription polymerase chain reaction (RT-PCR) and quantitative polymerase chain reaction (qPCR) analyses of galanin-like peptide (Galp), alarin (Ala), galanin receptor 1 (Galr1), galanin receptor 2 (Galr2), galanin receptor 3 (Galr3), and neurotrophic receptor tyrosine kinase 2 (Ntrk2; also known as TrkB). Oligonucleotide sequences for sense (S) and antisense (A) primers are shown. Hypoxanthine phosphoribosyltransferase (Hprt) was the reference gene

\begin{tabular}{|c|c|c|c|c|c|}
\hline cDNA & $\begin{array}{c}\text { Genbank } \\
\text { accession number }\end{array}$ & Primer & Primer sequence $\left(5^{\prime}-3^{\prime}\right)$ & Position & $\begin{array}{l}\text { PCR product } \\
\text { size [bp] }\end{array}$ \\
\hline Galp & NM_022633.1 & $\begin{array}{l}S \\
A\end{array}$ & $\begin{array}{l}\text { TGCTCACAGGGGACGAGGA } \\
\text { CCGGAACATTCTTGTCCAC }\end{array}$ & $\begin{array}{l}200-218 \\
429-447\end{array}$ & 248 \\
\hline Ala & NM_022633.1 & S & $\begin{array}{c}\text { ACAGGTCCTCCACCTTTCC } \\
\text { CATTGACCTTTTGGTCATCCTTGG }\end{array}$ & $\begin{array}{l}205-233 \\
314-337\end{array}$ & 133 \\
\hline Galr1 & NM_012958.3 & $\begin{array}{l}S \\
A\end{array}$ & $\begin{array}{l}\text { TTCATCGGGACAGCAACCA } \\
\text { GCCAAATACCACAACGACCA }\end{array}$ & $\begin{array}{l}755-774 \\
974-994\end{array}$ & 239 \\
\hline Galr2 & NM_019172.5 & S & $\begin{array}{l}\text { CATCCTGTGCTGCGTGCC } \\
\text { CTAGCCCCCAGATGAGCCC }\end{array}$ & $\begin{array}{l}251-269 \\
468-487\end{array}$ & 236 \\
\hline Galr3 & NM_019173.1 & $\begin{array}{l}S \\
A\end{array}$ & $\begin{array}{c}\text { AGGACTGAGGAAGATGGCTGA } \\
\text { ATTGCCCACCATGCCCAAC }\end{array}$ & $\begin{array}{c}13-34 \\
112-131\end{array}$ & 118 \\
\hline Ntrk2 & NM_012731.2 & S & $\begin{array}{l}\text { TCGGATGACAGTGGGAAACAA } \\
\text { TGAAGTGCTGGCTTGGGGT }\end{array}$ & $\begin{array}{l}1430-1451 \\
1592-1608\end{array}$ & 179 \\
\hline
\end{tabular}




\section{Results}

\section{Expression analysis of Ala, Galp and their receptors in the hypothalamo- pituitary-adrenal axis during postnatal ontogenesis}

The studies were carried out on male rats at the age of 2-360 days. The expression of Ala gene was observed in the hypothalamus, the hypophysis and the adrenal glands (Fig. 1). The level of expression of this gene increased in rats on the $120^{\text {th }}$ and $360^{\text {th }}$ day of life. An elevated level of expression of this gene was observed in the pituitary of 2-day rats, while very low levels of Ala mRNA were observed in the adrenals; however, they did not change during ontogenesis. On the other hand, in the course of postnatal ontogenesis, Galp gene expression was observed in the hypothalamus and the hypophysis, while in the adrenal glands it was negligible throughout the period under study (Fig. 1). In the hypothalamus, this expression increased temporarily in rats on the $120^{\text {th }}$ day of life, and in the pituitary - on the $2^{\text {nd }}$ day after birth.

The expression of Galrl gene was observed in the hypothalamus and the adrenal glands of a growing rat, but it was negligible in the hypophysis (Fig. 2). In the course of ontogenesis, the level of expression of this gene did not change in the hypothalamus, but increased in the adrenals of the oldest rats studied. The presence of Galr2 mRNA was noted in the hypothalamus, the hypophysis and the adrenal glands of a growing rat (Fig. 2). During ontogenesis, the level of expression of the gene did not change in the hypothalamus and the pituitary, but increased temporarily in the adrenals of 60-day rats. The presence of Galr3 mRNA was also found in all examined organs of a growing rat (Fig. 2). During ontogenesis, the level of expression of the gene increased only at individual observation points: the hypothalamus - day 120, the hypophysis - day 360 , and the adrenals - day 120 . The expression of Ntrk2 gene was demonstrated in all studied organs. In the course of postnatal ontogenesis, it did not change in the hypothalamus, but increased in the pituitary and the adrenal glands of the rat on the $21^{\text {st }}$ day of life.

\section{Expression analysis of Ala, Galp and their receptors in different compartments of the adrenal glands of adult, intact male and female rats}

In these studies, the levels of expression of the studied genes were determined using the $\mathrm{qPCR}$ method in individual compartments ( $\mathrm{ZG}, \mathrm{ZF} / \mathrm{R}, \mathrm{M})$ of the adrenal glands of male and female rats. In all these cases, the expression of Ala, Galp and Galr1 genes was negligible (data not shown). The expression of Galr2, Galr3 and Ntrk2 genes was demonstrated in all adrenal compartments of rats of both sexes (Fig. 3). Their expression was similar in all adrenal zones in males. In females, Galr2 expression was higher in ZF/R than in other compartments. The expression of Ntrk2 gene, on the other hand, was the highest in ZG.

\section{Expression analysis of Ala, Galp and their receptors in the hypothalamo- pituitary-adrenal axis of rats administered adrenocorticotropic hormone}

Within 60 min after ACTH administration, the level of expression of the studied neuropeptide genes in the pituitary and the adrenal glands of male rats did not change (data not shown). Similarly, in the hypothalamus, the expression of Ala and Galp genes did not change, but the level of expression of Galr1 gene decreased (Fig. 4).
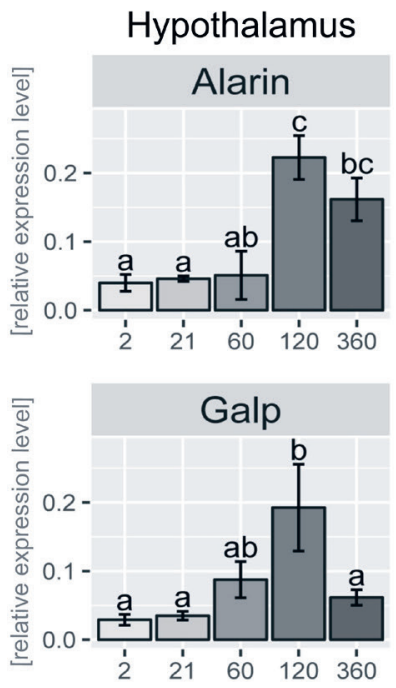
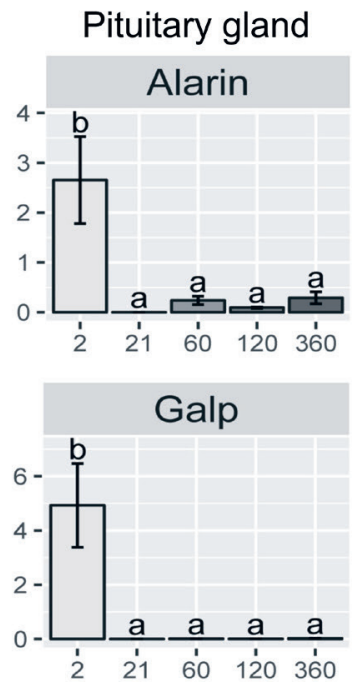
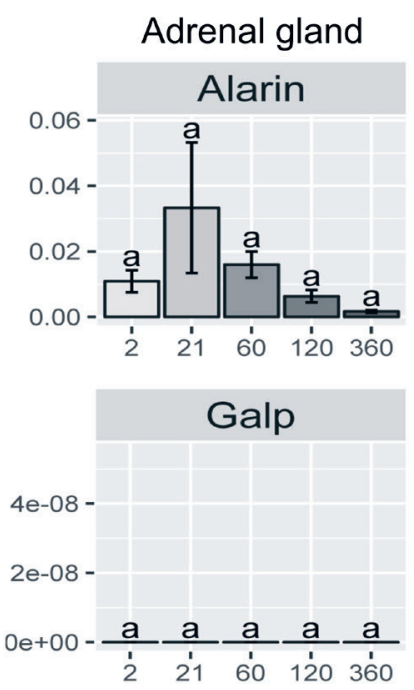

Fig. 1. Relative expression of Ala and Galp mRNAs in the hypothalamus, the pituitary and the adrenal glands of male rats during postnatal ontogenesis (days 2-360). Reverse transcription-quantitative polymerase chain reaction (RT-qPCR) was performed to determine the mRNA expression levels

Data is presented as the mean \pm standard error of the mean (SEM); $n=5$ per group. Statistical analysis of the data was performed using one-way analysis of variance (ANOVA) followed by Tukey's post-hoc test. Groups sharing the same letter are not significantly different, while different letters indicate groups that are significantly different from each other, with $p<0.05$. 

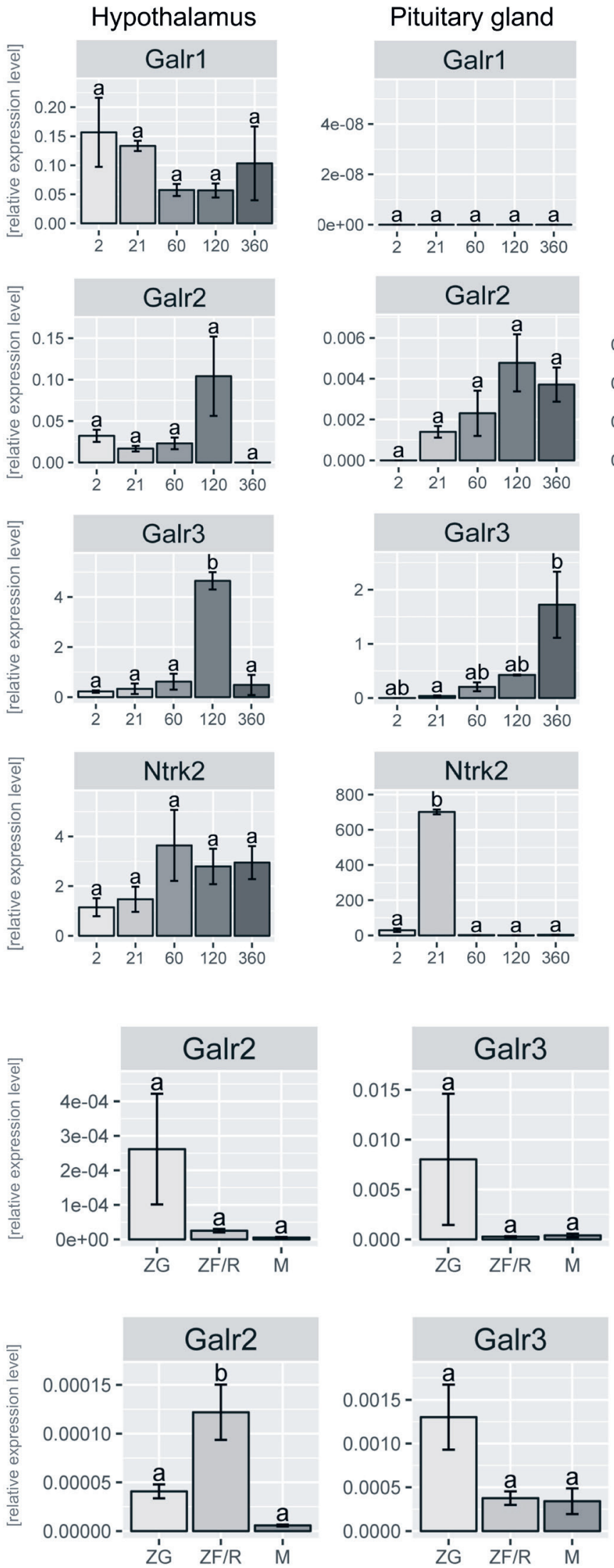

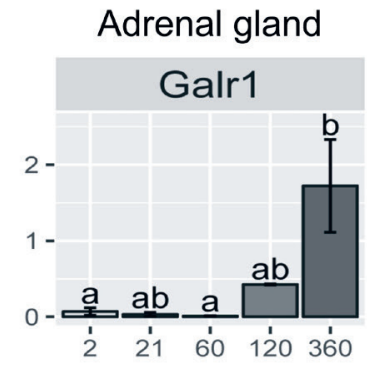

Fig. 2. Relative mRNA expression of Galr1-3 and Ntrk2 genes

in the hypothalamus, the pituitary and the adrenal glands of male rats during postnatal ontogenesis (days 2-360).

Reverse transcription-quantitative polymerase chain reaction was performed to determine the mRNA expression levels

Data and statistical analysis as in Fig. 1; $\mathrm{n}=5$ per group.
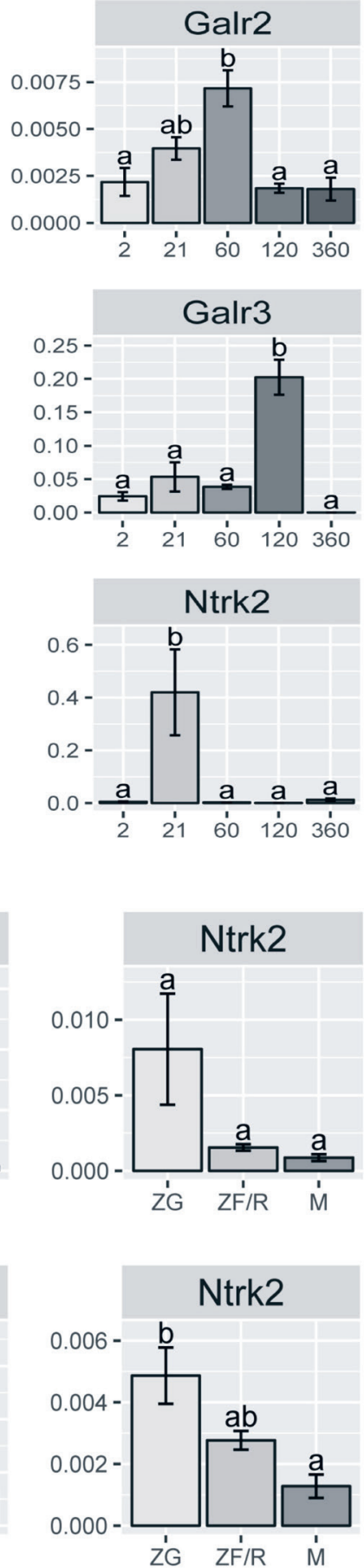

Fig. 3. Relative mRNA expression of Galr2-3 and Ntrk2 genes in different compartments of the adrenal glands of adult, intact male (upper row) and female rats. Reverse transcriptionquantitative polymerase chain reaction was performed to determine the mRNA expression levels

Data and statistical analysis as in Fig. 1; $\mathrm{n}=6$ per group; $\mathrm{ZG}$ - zona glomerulosa; ZF/R - zona fasciculata/ reticularis; $\mathrm{M}$ - medulla. 

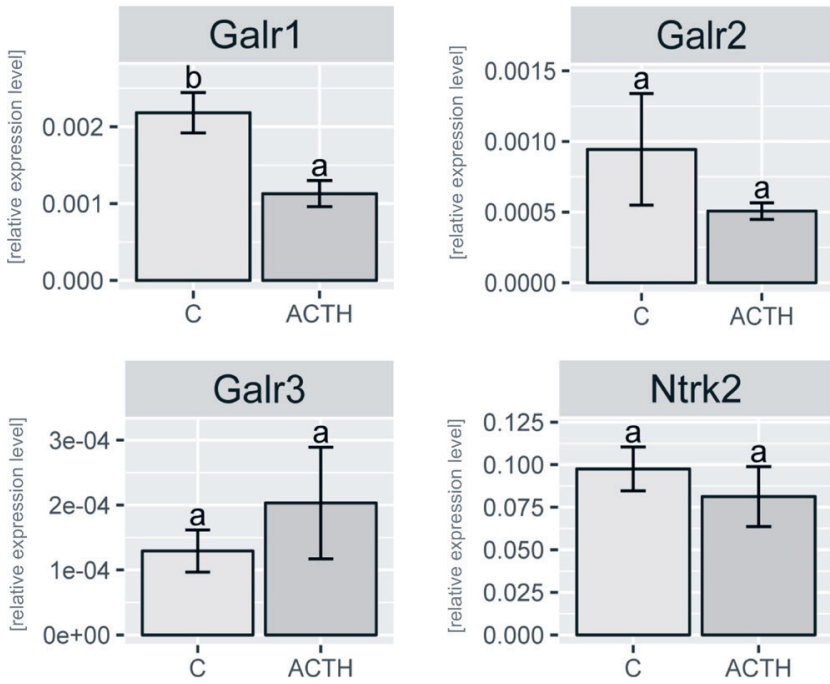

Fig. 4. Relative mRNA expression of Galr1-3 and Ntrk2 genes in the hypothalamus adult male rats administered adrenocorticotropic hormone (ACTH). Adrenocorticotropic hormone (Cortrosyn $\left.{ }^{\circledR}\right)$ was administered by intraperitoneal (ip.) injection at a dose of $2.5 \mu \mathrm{g} / 100 \mathrm{~g}$. Control rats were administered $0.2 \mathrm{~mL}$ physiological saline $(0.9 \%$ $\mathrm{NaCl}$ ). Rats were decapitated $1 \mathrm{~h}$ after injection. Reverse transcriptionquantitative polymerase chain reaction was performed to determine the mRNA expression levels

Data and statistical analysis as in Fig. 1; $n=5$ per group.

\section{Enucleation-induced adrenocortical regeneration}

Enucleation-induced adrenal regeneration is one of the types of in vivo gland growth. The data obtained from the microarray analysis suggested the expression of Galp, Galr1-3 receptors and Ntrk2 receptor genes in the regenerating adrenals of the rat. This data was validated using the qPCR method and showed only a minimal expression of Galp, Ala, Galr1, and Galr3 genes. In the regenerating adrenal glands, the expression of Galr2 gene, which even at the last point of the study (15 days) was much lower than in the control (Fig. 5), decreased significantly. The levels of Ntrk2 mRNA did not change throughout the observed regeneration period of the adrenals.

\section{Compensatory adrenal growth}

Unilateral adrenalectomy-induced compensatory adrenal growth is another type of growth of the gland. As in the case of enucleation-induced adrenal regeneration, the data from the microarray analysis suggested the expression of both neuropeptides (Galp and Ala) and their receptors in the growing adrenals. However, the validation of the data by means of qPCR in the studied adrenals did not reveal the expression of Ala, Galp and Galr1 genes (data not shown). Compared to the control, the expression of Galr2, Galr3 and Ntrk2 genes in the adrenal gland after hemiadrenalectomy did not change within $72 \mathrm{~h}$ after surgery (Fig. 6).

\section{Discussion}

Body weight regulation and energy homeostasis is controlled by a myriad of metabolic pathway intermediates and endocrine control systems. There are 2 principal mechanisms of energy homeostasis regulation, central and peripheral. Peptides involved in food intake - orexigenic, such as NPY, agouti-related peptide (AgRP), orexins (Ox), apelin (Apln), Gal, and anorexigenic, such as cocaine- and amphetamine-regulated transcript (CART), proopiomelanocortin (Pomc) and Crh, play a significant role in these regulatory processes. It is well known that glucocorticoids stimulate/inhibit the secretion of numerous orexigenic and anorexigenic peptides, which in turn control the growth, structure and function of the adrenal gland. ${ }^{25,26}$ Today, the group of neuropeptides involved in the regulation
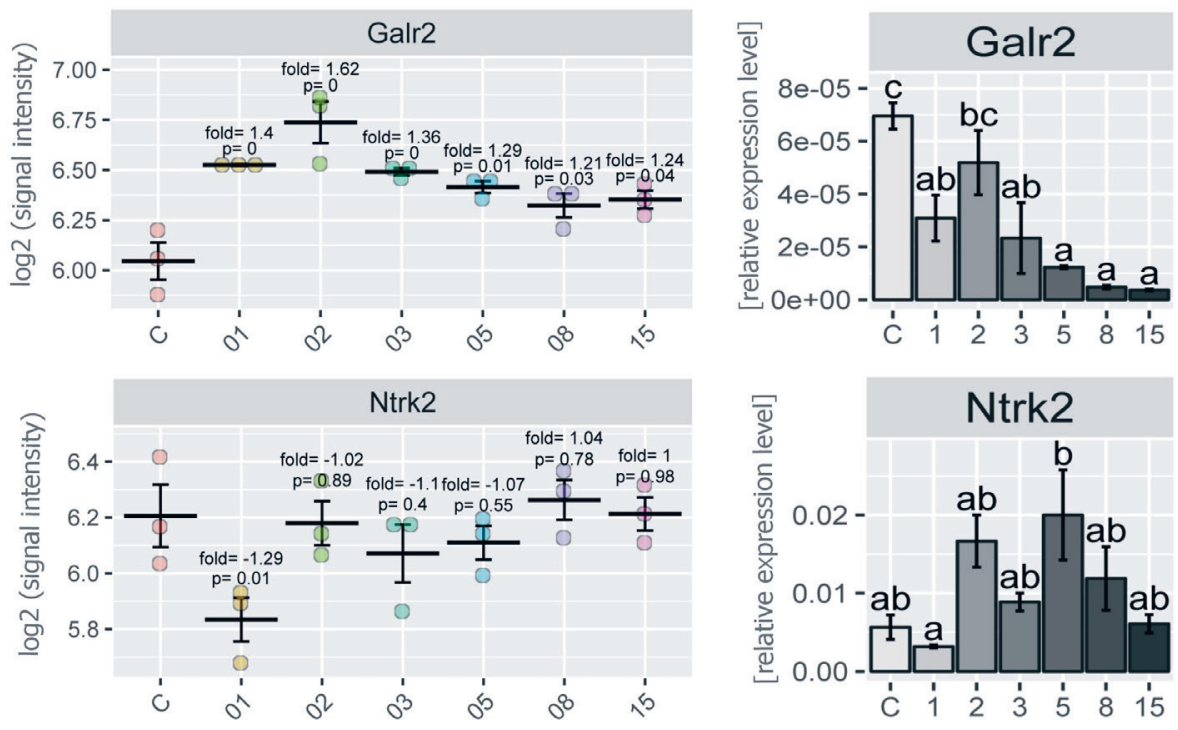

Fig. 5. Relative expression levels of adrenal Galr2 and Ntrk2 genes in the course of enucleationinduced adrenal regeneration. Adult female rats were sacrificed $1,2,3,5,8$, and 15 days after surgery. The adrenals from sham-operated rats (day 1 after surgery) were used as control glands

Reanalyzed microarray data (graphs on the left) was obtained from an earlier study. ${ }^{21}$ Graphs on the right (bars) present data obtained in $\mathrm{QPCR}$. Each circle represents a single rat. Data and statistical analysis as in Fig. 1. 

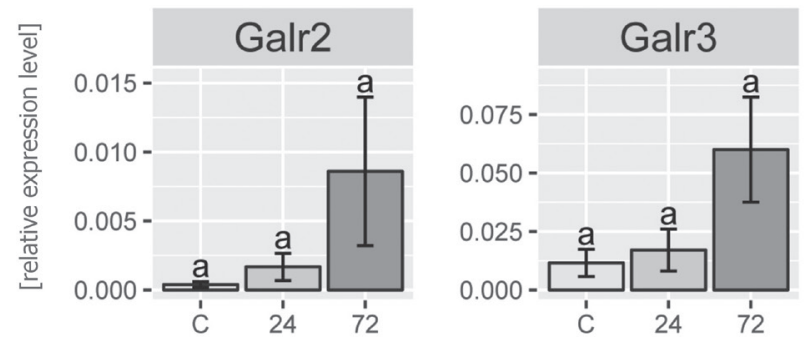

of energy homeostasis includes 2 subsequent peptides of galanin peptide family - Galp and Ala.

Galp was isolated and cloned as an endogenous ligand of Galr2, but a later study provided evidence that Galp interacted also with other Gal receptor isoforms, such as Galr1 and Galr3. ${ }^{3,4}$ This is most probably due to the fact that the amino acids 9-21 of Galp peptide are identical to the first 13 amino acids of Gal peptide. This sequence of amino acids is able to activate Gal receptors. ${ }^{3}$ Furthermore, studies on genetic knockouts of Galr1, Galr2 and Galr3 suggested that the effect of Galp might not be dependent on Gal receptors in the regulation of feeding. ${ }^{27-29}$ However, no other receptors through which Galp could regulate food intake have yet been identified.

Previously, it has also been suggested that Ala exerts a biological effect through known Gal receptors. The exclusion (deletion) of exon 3 in Galp mRNA in post-translational processes, however, led to a loss of the Gal receptor binding domain of Ala, which is a key site for the binding of Galp to Gal receptors. And in fact, Ala is unable to bind to membranes expressing Gal receptors, and therefore it has been suggested that Ala acts through an unidentified receptor(s)..$^{23,30}$ Regarding this, only recently, in 2017, Zhuang et al. demonstrated that Ala might act through TrkB receptor (receptor for brain-derived neurotrophic factor; known also as Ntrk2) in its antidepressant activity and cause changes in ERK and AKT signaling pathways. ${ }^{31}$

Galp is known to be involved in the neuroendocrine regulation of feeding, body weight and temperature. It was demonstrated earlier that intracerebroventricular (icv.) infusion of Galp stimulated food intake in rats in the first 2 h. ${ }^{6,32-34}$ This acute effect of Galp was at first identical to the feeding response observed after icv. injection of Gal; however, $24 \mathrm{~h}$ after Galp administration, both food intake and body weight decreased. ${ }^{6,33}$ These observations pointed to the possibility that Galp could have dual and opposing effects on energy homeostasis. On the other hand, the other peptide (Ala) was demonstrated to be involved in the regulation of feeding behavior in male rats. Regarding this, Boughton et al. found that acute icv. Ala administration stimulated food intake and increased circulating luteinizing hormone (LH) levels in male rats. ${ }^{30}$

All the above information suggests that both Galp and Ala may be involved in the regulation of energy homeostasis. In this context, immunohistochemical studies

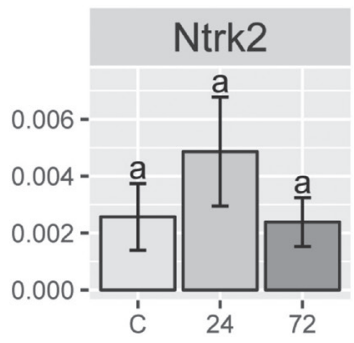

Fig. 6. Relative expression levels of adrenal Galr2-3 and Ntrk2 genes in the course of the compensatory adrenal growth. Adult male rats were hemiadrenalectomized and their adrenals studied after 24 and $72 \mathrm{~h}$. Animals from the sham-operated group (control) were decapitated $24 \mathrm{~h}$ after the sham surgery. Reverse transcription-quantitative polymerase chain reaction was performed to determine the mRNA expression levels

Data and statistical analysis as in Fig. 1; $n=10$ per group.

demonstrated that ca. $85 \%$ of ARC-Galp-positive neurons also expressed leptin receptors. ${ }^{10}$ Other Galp neurons express orexin-1 receptors and melanocyte-stimulating hormone (MSH). Some Galp-positive cells are innervated by NPY- and Ox-terminals, while Ox- and MCH-neurons of the lateral hypothalamus and gonadotropin-releasing hormone (GnRH)-neurons are innervated by Galp. ${ }^{35}$ Moreover, Ala-like immunoreactivity is present in the locus coeruleus (LC) and the ARC of rats and mice. Both regions are known to be involved in feeding behavior.

Taking into account the interrelationships between corticosteroids, orexigenic and anorexigenic neuropeptides, we analyzed the expression patterns of Galp and Ala mRNAs and their receptors in individual components of the rat's HPA axis. In further experiments, we investigated the expression patterns of these neuropeptides and their receptors during ontogenesis, after adrenal stimulation with corticotropin, in compensatory adrenal growth, and in the course of enucleation-induced adrenal regeneration.

Considering the presence and role of the galaninergic system in the HPA axis, the role of Gal itself and its receptors is relatively well known. ${ }^{16}$ Data for Galp and Ala in this system is limited.

Immunohistochemical studies and in situ hybridization show that cells expressing Galp peptide are located almost exclusively in the hypothalamic ARC and median eminence as well as in the posterior pituitary of both rats and mice. ${ }^{8-10,36}$ The analysis of the expression of both peptides at the RNA level, based on the qPCR method, presented by us confirms previous reports - Galp and Ala peptide mRNA is expressed both in the hypothalamus and in the pituitary glands, but not in the adrenals. It is interesting to note that in the hypothalamus, the expression of both Galp and Ala mRNA was low in the first days of postnatal ontogenesis, and then it increased statistically significantly, especially on the $120^{\text {th }}$ day of the development, while the expression of both genes in the pituitary was high on the $2^{\text {nd }}$ day of ontogenesis, and then it decreased significantly.

In the available literature, there are many reports concerning the expression of Gal receptors. There is a consensus that the expression of Galr1 and Galr3 mRNA occurs mainly in the central nervous system, while the expression of Galr2 is widespread throughout the body. ${ }^{37}$ Previous data indicates that in rats, within the HPA axis, 
Galr1-3 receptors are expressed in the hypothalamus and Galr1 receptors are not expressed in the pituitary gland. The expression of Galr2 and Galr3 was also described in the adrenal gland, both in the cortex and in the medulla of the gland. The expression of various isoforms of Ntrk2 was also described in the hypothalamus and in the pituitary gland, while in the adrenal glands of rats it was negligible. ${ }^{38,39}$

Only a few publications on the expression of Galp, Ala and their receptors during ontogenesis are available. The results of our studies indicate a very variable and diversified expression of the studied genes in the HPA system in the course of ontogenesis. Ala and Galp mRNAs were found to be present in the hypothalamus and in the hypophysis; however, in the adrenal gland only Galp mRNA was identified. Our research indicates that the level of expression of Galp and Ala genes in the hypothalamus of the rat is low in the initial periods of postnatal development and it increases on the $120^{\text {th }}$ day of life. In the pituitary gland, in turn, the level of expression of both genes was high on the $2^{\text {nd }}$ day of ontogenesis, after which it decreased significantly. In general, the expression of the studied receptors (Galr1-3 and Ntrk2) in the HPA axis during the rat ontogenesis is consistent with the above data. The levels of Galr1 mRNA did not change in the hypothalamus, but increased in the adrenals of the oldest animals. The expression of other receptors of the studied system did not show any significant changes in the hypothalamus, in the pituitary gland or the adrenal glands, either. In an earlier publication, Faure-Virelizier et al. observed a higher expression of Galr1 gene in the hypothalamus of adult female rats compared to male rats. ${ }^{40}$ We have not shown such a difference in our research.

In this study, we also analyzed the expression of the studied genes in various adrenal compartments of adult male and female rats. It is well known that adult adrenal glands of female rats differ from male adrenal glands of the same age. This difference appears after puberty and is dependent on sex hormones since testosterone exerts an inhibitory effect on the HPA axis. ${ }^{17,19}$ The expression of Ala, Galp and Galr1 genes was negligible in all adrenal glands of males and females. The expression of Galr2, Galr3 and Ntrk2 genes was observed in all samples studied, with the level of this expression being similar in $\mathrm{ZG}, \mathrm{ZF} / \mathrm{R}$ and $M$. The only exception is the expression of Galr2 gene in adult females, which in ZF/R was higher than in ZG and $M$. The obtained results suggest that the expression of the studied genes of the galaninergic system in the adrenal glands of adult rats does not show any differences depending on sex.

The results obtained by us in the adrenals of the rat confirm the data obtained by Yu et al. ${ }^{39}$ Using the RNA-seq method, the authors studied gene expression, among others, in the adrenals of the Fischer strain of rats, males and females, in 4 developmental periods: juvenile ( 2 weeks), adolescence (6 weeks), adult (21 weeks) and aged (104 weeks).
In the adrenals of these rats, the authors did not show the expression of Galp gene. A very low expression of Galr1 gene was observed only in adolescent rats. The expression of Galr2, Galr3 and Ntrk2 genes took place at all stages of ontogenetic development, with the level of this expression not changing during ontogenesis. In addition, Yu et al. did not observed any sex differences in the expression of these genes in the adrenals. ${ }^{39}$

The next step of the study was to investigate the effect of acute administration of ACTH on the expression of the studied genes in the HPA axis of the rat. Within 60 min after a single administration of ACTH, no statistically significant changes in the level of expression of the examined genes were observed in the analyzed system (the HPA axis). The only exception was the expression of Galr1 gene in the hypothalamus, which decreased significantly. This may suggest that the galaninergic system of the HPA axis in the rat can be regulated by ACTH via Galr1.

In the present research we also examined the expression of Galp and Ala genes and their receptors in the enucleation-induced regeneration of the adrenal gland of the rat and in the compensatory adrenal growth induced by hemiadrenalectomy. These tests were based on microarrays, the results of which were validated by means of qPCR. It is well known that data obtained from microarray analyses usually indicates a larger number of differentially expressed genes; therefore, the data from qPCR seems to be more reliable. With qPCR we showed only an insignificant expression of Galp, Galr1-3 receptors and Ntrk2 receptor genes in the regenerating adrenal glands of the rat. During gland regeneration, however, the expression of Galr2 gene decreased significantly, while the expression of Ntrk2 did not change. The expression of the studied genes did not change also in the case of the compensatory adrenal growth. The obtained results suggest that Galp, Ala and their receptors do not play a significant role in the adrenal growth caused by ACTH elevation (i.e., in enucleationinduced regeneration) or hemiadrenalectomy (neurally depending growth).

To summarize, we conducted systematic studies on the expression of Galp, Ala, Galr1-3, and Ntrk2 genes in the HPA axis of rats, with particular emphasis on the adrenal glands. These genes show different expression within the studied axis, some of them are not expressed, whether in the hypothalamus, the pituitary gland or the adrenal glands. In the course of adrenal ontogenesis, no significant changes in the level of expression of the studied genes were observed. Apart from Galr2, the expression of the studied genes did not change in the enucleation-induced adrenal gland regeneration. These observations suggest that neither Galp nor Ala plays a significant role in the growth of the rat adrenal glands. After acute administration of ACTH, the expression of Galr1 in the hypothalamus significantly decreased in the studied axis. Our observations suggest that corticotropin may regulate the expression of genes of the galaninergic system of the hypothalamus. 


\section{References}

1. Hökfelt T, Tatemoto K. Galanin - 25 years with a multitalented neuropeptide. Cell Mol Life Sci. 2008;65(12):1793-1795.

2. Lang R, Gundlach AL, Kofler B. The galanin peptide family: Receptor pharmacology, pleiotropic biological actions, and implications in health and disease. Pharmacol Ther. 2007;115(2):177-207.

3. Ohtaki T, Kumano S, Ishibashi Y, et al. Isolation and cDNA cloning of a novel galanin-like peptide (GALP) from porcine hypothalamus. J Biol Chem. 1999;274(52):37041-37045.

4. Lang R, Berger A, Santic R, et al. Pharmacological and functional characterization of galanin-like peptide fragments as potent galanin receptor agonists. Neuropept. 2005;39:(3)179-184.

5. Santic R, Fenninger K, Graf K, et al. Gangliocytes in neuroblastic tumors express alarin, a novel peptide derived by differential splicing of the galanin-like peptide gene. J Mol Neurosci. 2006;29(2):145-152.

6. Krasnow SM, Fraley GS, Schuh SM, Baumgartner JW, Clifton DK, Steiner RA. A role for galanin-like peptide in the integration of feeding, body weight regulation, and reproduction in the mouse. Endocrinol. 2003;144(3):813-822.

7. Patterson M, Murphy KG, Thompson EL, et al. Microinjection of galaninlike peptide into the medial preoptic area stimulates food intake in adult male rats. J Neuroendocrinol. 2006;18(10):742-747.

8. Juréus A, Cunningham MJ, McClain ME, Clifton DK, Steiner RA. Galanin-like peptide (GALP) is a target for regulation by leptin in the hypothalamus of the rat. Endocrinol. 2000;141(7):2703-2706.

9. Larm JA, Gundlach AL. Galanin-like peptide (GALP) mRNA expression is restricted to arcuate nucleus of hypothalamus in adult male rat brain. Neuroendocrinol. 2000;72(2):67-71.

10. Takatsu $Y$, Matsumoto $H$, Ohtaki T, et al. Distribution of galanin-like peptide in the rat brain. Endocrinol. 2001;142(4):1626-1634.

11. Gundlach AL. Galanin/GALP and galanin receptors: Role in central control of feeding, body weight/obesity and reproduction? Eur J Pharmacol. 2002;440(2-3):255-268.

12. Crawley JN, Austin MC, Fiske SM, et al. Activity of centrally administered galanin fragments on stimulation of feeding behavior and on galanin receptor binding in the rat hypothalamus. J Neurosci. 1990;10(11):3695-3700.

13. Shiba K, Kageyama H, Takenoya F, Shioda S. Galanin-like peptide and the regulation of feeding behavior and energy metabolism. FEBS J. 2010;277(24):5006-5013.

14. Corder R, Pralong F, Turnill D, Saudan P, Muller AF, Gaillard RC. Dexamethasone treatment increases neuropeptide $Y$ levels in rat hypothalamic neurones. Life Sci. 1988;43(23):1879-1886.

15. Malendowicz LK, Tortorella C, Nussdorfer GG. Orexins stimulate corticosterone secretion of rat adrenocortical cells, through the activation of the adenylate cyclase-dependent signaling cascade. J Steroid Biochem Mol Biol. 1999;70(4-6):185-188.

16. Tortorella C, Neri G, Nussdorfer GG. Galanin in the regulation of the hypothalamic-pituitary-adrenal axis (Review). Int $J$ Mol Med. 2007;19(4):639-647.

17. Jopek K, Tyczewska M, Celichowski P, Malendowicz LK, Rucinski M. Transcriptome profile in unilateral adrenalectomy-induced compensatory adrenal growth in the rat. Int J Mol Sci. 2018;19(4):1111.

18. Rucinski M, Ziolkowska A, Szyszka M, Hochol A, Malendowicz LK. Evidence suggesting that ghrelin O-acyl transferase inhibitor acts at the hypothalamus to inhibit hypothalamo-pituitary-adrenocortical axis function in the rat. Peptides. 2012;35(2):149-159.

19. Trejter M, Jopek K, Celichowski P, Tyczewska M, Malendowicz LK, Rucinski M. Expression of estrogen, estrogen related and androgen receptors in adrenal cortex of intact adult male and female rats. Folia Histochem Cytobiol. 2015;53(2):133-144.

20. Paschke L, Zemleduch T, Rucinski M, Ziolkowska A, Szyszka M, Malendowicz LK. Adiponectin and adiponectin receptor system in the rat adrenal gland: Ontogenetic and physiologic regulation, and its involvement in regulating adrenocortical growth and steroidogenesis. Peptides. 2010;31(9):1715-1724.
21. Tyczewska M, Rucinski M, Trejter M, Ziolkowska A, Szyszka M, Malendowicz LK. Angiogenesis in the course of enucleation-induced adrenal regeneration - expression of selected genes and proteins involved in development of capillaries. Peptides. 2012;38(2):404-413.

22. Gentleman RC, Carey VJ, Bates DM, et al. Bioconductor: Open software development for computational biology and bioinformatics. Genome Biol. 2004;5(10):80.

23. Santic R, Schmidhuber SM, Lang $R$, et al. Alarin is a vasoactive peptide. Proc Natl Acad Sci U S A. 2007;104(24):10217-10222.

24. Benjamini $Y$, Hochberg Y. Controlling the false discovery rate: A practical and powerful approach to multiple testing. J R Stat Soc Ser B. 1995;57:289-300.

25. Hochol A, Tortorella C, Rucinski M, Ziolkowska A, Nussdorfer GG, Malendowicz LK. Effects of neuropeptides $B$ and $W$ on the rat pituitary-adrenocortical axis: In vivo and in vitro studies. Int J Mol Med. 2007;19(2):207-211.

26. Rucinski M, Ziolkowska A, Szyszka M, Malendowicz LK. Cerebellin and des-cerebellin exert ACTH-like effects on corticosterone secretion and the intracellular signaling pathway gene expression in cultured rat adrenocortical cells - DNA microarray and QPCR studies. Int J Mol Med. 2009;23(4):539-546.

27. Fraley GS, Shimada I, Baumgartner JW, Clifton DK, Steiner RA. Differential patterns of Fos induction in the hypothalamus of the rat following central injections of galanin-like peptide and galanin. Endocrinol. 2003;144(4):1143-1146.

28. Krasnow SM, Hohmann JG, Gragerov A, Clifton DK, Steiner RA. Analysis of the contribution of galanin receptors 1 and 2 to the central actions of galanin-like peptide. Neuroendocrinol. 2004;79(5):268-277.

29. Man PS, Lawrence CB. The effects of galanin-like peptide on energy balance, body temperature and brain activity in the mouse and rat are independent of the GALR2/3 receptor. J Neuroendocrinol. 2008; 20(1):128-137.

30. Boughton CK, Patterson M, Bewick GA, et al. Alarin stimulates food intake and gonadotrophin release in male rats. Br J Pharmacol. 2010; 161(3):601-613.

31. Zhuang F, Li M, Gao X, et al. The antidepressant-like effect of alarin is related to TrkB-mTOR signaling and synaptic plasticity. Behav Brain Res. 2016;313:158-171.

32. Lawrence CB, Baudoin FM, Luckman SM. Centrally administered galanin-like peptide modifies food intake in the rat: A comparison with galanin. J Neuroendocrinol. 2002;14(11):853-860.

33. Lawrence CB, Williams T, Luckman SM. Intracerebroventricular galanin-like peptide induces different brain activation compared with galanin. Endocrinol. 2003;144(9):3977-3984.

34. Seth A, Stanley S, Dhillo W, Murphy K, Ghatei M, Bloom S. Effects of galanin-like peptide on food intake and the hypothalamo-pituitary-thyroid axis. Neuroendocrinol. 2003;77(2):125-131.

35. Takenoya F, Hirayama M, Kageyama H, et al. Neuronal interactions between galanin-like-peptide- and orexin- or melanin-concentrating hormone-containing neurons. Regul Pept. 2005;126(1-2):79-83.

36. Eberhard N, Mayer C, Santic R, et al. Distribution of alarin immunoreactivity in the mouse brain. J Mol Neurosci. 2012;46(1):18-32.

37. Lang R, Gundlach AL, Kofler B. The galanin peptide family: Receptor pharmacology, pleiotropic biological actions, and implications in health and disease. Pharmacol Ther. 2007;115(2):177-207.

38. Otani K, Okada M, Yamawaki H. Diverse distribution of tyrosine receptor kinase B isoforms in rat multiple tissues. J Vet Med Sci. 2017;79(9): 1516-1523.

39. Yu Y, Fuscoe JC, Zhao C, et al. A rat RNA-Seq transcriptomic BodyMap across 11 organs and 4 developmental stages. Nat Commun. 2014; 5:3230.

40. Faure-Virelizier C, Croix D, Bouret $S$, et al. Effects of estrous cyclicity on the expression of the galanin receptor $\mathrm{Gal}-\mathrm{R} 1$ in the rat preoptic area: A comparison with the male. Endocrinol. 1998;139(10):4127-4139. 